\title{
Perancangan Sistem Informasi Menggunakan Enterprise Architecture Planning (Studi Kasus Pada Kecamatan di Kota Samarinda)
}

\author{
Anton Yudhana ${ }^{1 *}$, Rusydi Umar ${ }^{2}$, Faza Alameka ${ }^{3}$ \\ ${ }^{1}$ Jurusan Teknik Elektro \\ Universitas Ahmad Dahlan \\ D.I. Yogyakatra \\ ${ }^{2}$ Jurusan Teknik Informatika \\ Universitas Ahmad Dahlan \\ D.I. Yogyakarta \\ ${ }^{3}$ Magister Teknik Informatika \\ Universitas Ahmad Dahlan \\ D.I. Yogyakarta \\ *eyudhana@ee.uad.ac.id
}

\begin{abstract}
Abstrak-Perancangan sistem informasi pada kecamatan sering dijumpai ketidakselarasan dengan proses bisnis dan IT. Untuk dapat menggabungkan informasi dan mesinergikan bisnis dan IT di kecamatan yang ada di Kota Samarinda, maka diperlukan suatu perancangan sistem informasi. Dalam hal ini metode yang digunakan untuk menggambarkan kondisi organisasi saat ini dan merancang arsitektur enterprise adalah Enterprise Architecture Planning (EAP). Metode ini digunakan untuk menjabarkan dan merancang enterprise architecture yang tepat untuk mencapai tujuan bisnis pada kecamatan tersebut. Pada Penelitian yang dilakukan menghasilkan 5 kandidat entitas bisnis dan 8 kandidat aplikasi yang menjadi acuan pengembangan sistem informasi pada kecamatan di kota Samarinda.
\end{abstract}

Kata kunci: Perencanaan Arsitektur Enterprise, Sistem Informasi dan Teknologi Informasi, Kecamatan, Samarinda

\section{Pendahuluan}

Di era reformasi pada saat ini, masyarakat membutuhkan transparansi khususnya menyangkut program pembangunan yang diselenggarakan oleh pemerintah [1]. Pemerintah telah melakukan berbagai upaya untuk mewujudkan hal tersebut agar masyarakat mengetahui program-program yang dilaksanakan oleh pemerintah, salah satunya dengan bantuan SI (Sistem Informasi) [2]. Hal ini berkaitan dengan program e-government yang telah di dikeluarkan oleh pemerintah pusat [3].

Kemajuan ilmu pengetahuan dan teknologi (Iptek) sudah semakin luas terkhusus pada penggunaan Teknologi Informasi dan komunikasi (TIK) dan besar manfaatnya apabila diterapkan dalam hal meningkatkan pelayanan kepada masyarakat [4]. Bagi pemerintah di daerah yang tidak menggunakan tenologi yang sudah berkembang pada saat sekarang ini, sangatlah disayangkan padahal infrastruktur sangat mendukung untuk menerapkan e-government demi meningkatkan kualitas pelayanan publik.

Salah satu dampak dari pembangunan tanpa arah adalah susahnya penerapan e-government di instansi atau organisasi tersebut. Kendala dalam penerapan e-government itu sendiri adalah kesiapan sumber daya manusia dalam untuk mengelola e-government [5]. Pemerintahan yang di daerah dengan kondisi tidak menggunakan teknologi yang ada, sangat membutuhkan bantuan dari stakeholder agar pemerintah daerah mulai memanfaatkan TIK (Teknologi Informasi dan Komunikasi) untuk pelayanan masyarakat. Daerah yang dijadikan objek dalam penelitian ini adalah Kota Samarinda. Dalam penelitin ini dibahas mengenai pengembangan e-government di Kota Samarinda sehingga dihasilkan perancangan TIK yang lebih baik.

E-government bukanlah suatu proses yang mudah untuk mencapainya [6]. Agar hal ini bisa tercapai membutuhkan waktu yang sangat lama dan juga merupakan proses jangka panjang agar lebih terciptanya efektivitas untuk pelayanan kepada masyarakat. Tujuan dari e-Government di mana suatu pemerintahan melibatkan teknologi informasi untuk memperbaiki mutu (kualitas) pelayanan yang sedang berjalan [7]. Oleh sebab itu, diperlukan suatu metode perancangan strategis dalam pengembangan E-government itu sendiri

Kota Samarinda memiliki 10 kecamatan dan 52 kelurahan [8]. Tetapi hampir semua kecamatan di Samarinda belum memiliki master plan/road map untuk meningkatkan kualitas pelayanan publik mereka. Dalam hal ini dapat memunculkan beberapa permasalahan yaitu: tidak adanya kemauan dari pemerintah dalam menggunakan teknologi informasi, kurangnya SDM yang berkompeten, belum adanya divisi khusus TI yang ada di kecamatan tersebut. Oleh sebab itu, dibutuhkan sebuah master plan perancangan arsitektur e-government yang menyeluruh untuk kota Samarinda sehingga nantinya TIK dapat diimplementasikan dengan baik . 
Dengan melihat kondisi yang ada, maka penelitian yang dilakukan adalah membuat arsitektur enterprise sistem informasi pelayanan publik sebagai rencana strategis. Arsitektur enterprise merupakan secara salah satu cara untuk menggambarkan tentang sebuah enterprise secara logis dan menghasilkan sebuah kumpulan arsitektur yang meliputi bisnis, informasi, aplikasi dan teknologi [9]. EAP (Enterprise Architectur Planning) merupakan sebuah alur pengertian arsitektur dalam penggunaan informasi [10] dalam penerapan arsitektur tersebut. EAP merupakan strategi enterprise untuk menghadapi persaingan dan perkembangan sistem informasi [11]

Pada penelitian ini menghasilkan sebuah perancangan pengembangan TIK yang saling terhubung sebagai salah satu strategi pengembangan TIK dan implementasinya untuk kecamatan-kecamatan yang ada di Kota Samarinda. Enterprise Architecture Planning merupakan metode yang mengusulkan beberapa langkah terstruktur dalam proses perencanaan sistem informasi [11][12]. Pemilihan Enterprise Achitecture sebagai kerangka kerja dalam melakukan pengembangan TIK dibangun mampu menyesuaikan dengan pengembangan TIK di masa yang akan datang[11].

Hasil dari metode EAP merupakan sebuah dokumen perancangan pengembangan sistem informasi atau yang sering dibilang sebagai dokumen tata kelola organisasi dalam rentan waktu tertentu, di mana dalamnya berisikan berbagai kebutuhan dalam pengembangan sistem informasi dan perancangan strategis organisasi dalam mengimplementasikan dan membangun sistem informasi [13] dalam instasi tersebut.

\section{Tinjauan Pustaka}

\section{a. Penelitian yang relevan}

Pada penelian yang dilakukan [14], [15], [16], [10], [17], [18], [19], [20] melakukan penelitian menggunakan Enterprise architechture planning menggunakan kerangka zachman framework dalam dunia Pendidikan, yang menghasilkan beberapa perencanaan pengembangan sistem informasi dan teknologi informasi yang sesuai dengan kebutuhan dari lokasi masing-masing penelitian tersebut, sedangkan pada penelitan [21][22][23][24][25] dilakukan di lingkungan instansi pemerintahan dan menghasilkan beberapa perancangan yang sesuai dengan visi misi instasi tersebut.

Pada penelitan [26] [27] [28] menjelaskan seberapa penting pendekatan enterprise architecture planning dalam perencanaan strategis pengembangan sistem informasi dan teknologi informasi dalam suatu instansi swasta maupun instansi Pendidikan.

\section{b. EAP (Enterprise Architecture Planning)}

Enterprise Architecture Planning (EAP) merupakan sebuah cara yang dikembangkan untuk membangun sebuah arsitektur enterprise [29][10]. Tahapan pembangunan EAP menurut Spewak dkk merupakan tahap untuk memulai, memahami kondisi sekarang pada lokasi penelitian, pengertian visi dan misi pada masa depan, dan tahap untuk menyusun tahapan perencanaan dalam mencapai visi dan misi pada masa yang akan datang [10][30]

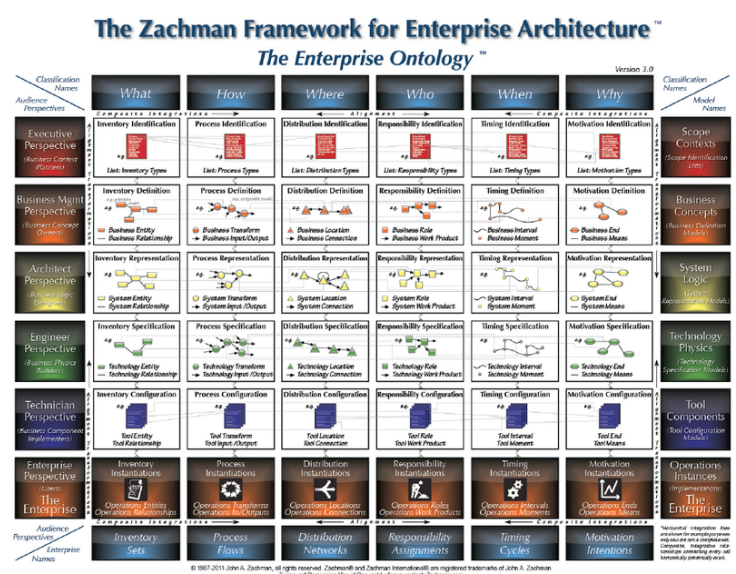

Gambar 2. Zachman Framework

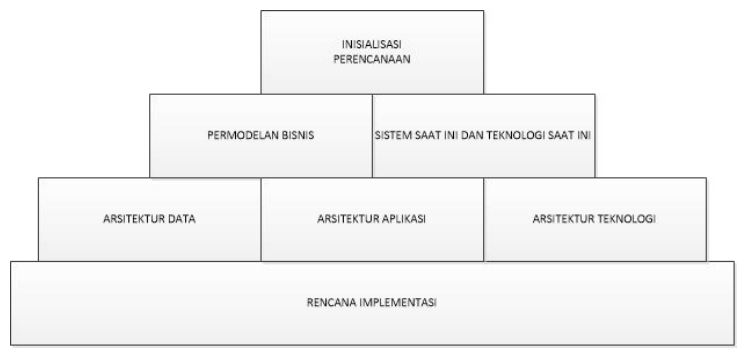

Gambar 1. Enterprise architecture planning

\section{c. Kerangka kerja $Z A C H M A N$ FRAMEWORK}

Zachman Framework merupakan skema untuk melakukan penggolongan-golongan organisasi, bagian pada Zachman Framework terdiri dari 6 kolom dan 6 baris. Tiap kolom merepresentasikan fokus, abstraksi, atau topik arsitektur enterprise. Tiap baris merepresentasikan perspektif berikut:

1. Perspektif Perencana: menetapkan konteks, latar belakang, \& tujuan.

2. Perspektif Pemilik: menetapkan model konseptual dari enterprise.

3. Perspektif Perancang: menetapkan model sistem informasi sekaligus menjembatani hal yang diinginkan pemilik \& hal yang dapat direalisasikan secara teknis dan fisik.

4. Perspektif Pembangun: menetapkan rancangan teknis \& fisik yang digunakan dalam mengawasi implementasi teknis dan fisik.

5. Perspektif Subkontraktor: menetapkan peran dan rujukan bagi pihak yang bertanggung jawab untuk melakukan pembangunan sistem informasi.

6. Perspektif Fungsional: merepresentasikan perspektif penguna dan wujud nyata hasil implementasi [31]

\section{Metode}

Penelitian ini mengacu pada metodologi dari Enterprise Architecture Planning (EAP)[10]. Langkah-langkah yang harus dilalui dengan baik agar pada penelitian yang dilaksanakan dapat berjalan dengan maksimal. 


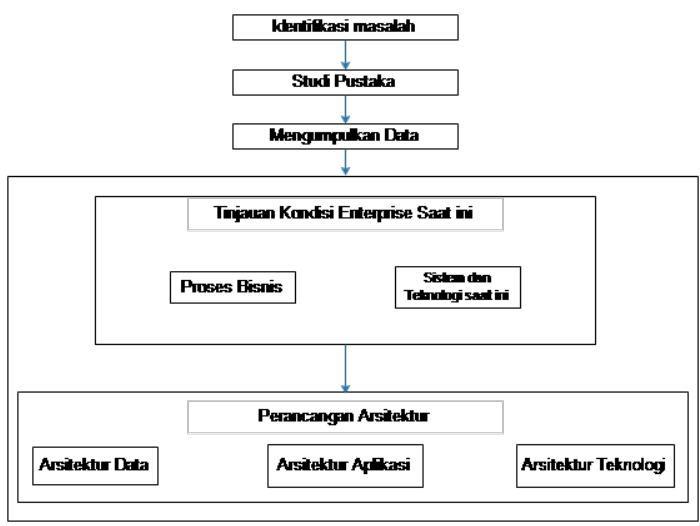

Gambar 3. Kerangka Penelitian

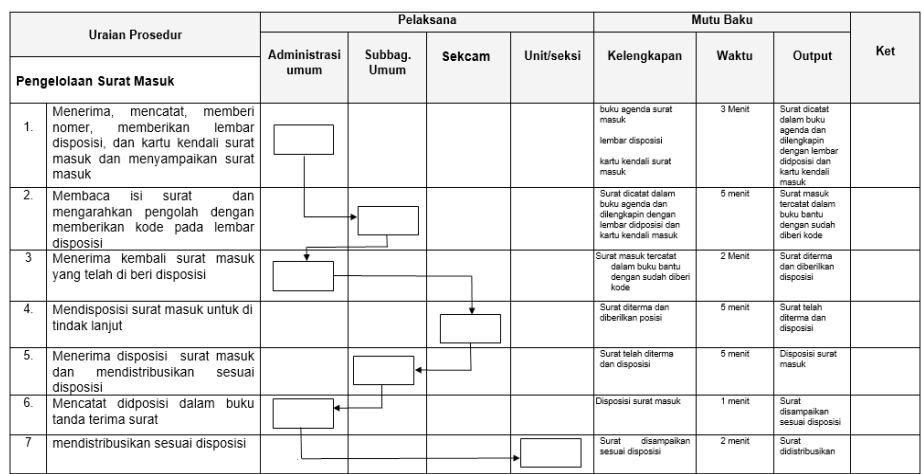

Gambar 4. Proses bisnis Surat masuk

\begin{tabular}{|c|c|c|c|c|c|c|c|c|}
\hline & & & & & & nutu Baku & & Keterangan \\
\hline No & Kegiatan & Camat & $\begin{array}{c}\text { Kasi } \\
\text { Pemerintan } \\
\text {. }\end{array}$ & Staf & Kelengliapan & waktu & Output & \\
\hline & & & & 4 & & 7 & & \\
\hline 1 & $\begin{array}{l}\text { Membuat SPPD dalam rangka } \\
\text { Penyusunan Profil Kecamatan }\end{array}$ & & & & SPT, Lembar SPPD & $1 \mathrm{jam}$ & $\begin{array}{l}\text { Diterimanya } \\
\text { surat } \\
\text { permohonan }\end{array}$ & $\begin{array}{l}\text { SOP } \\
\text { Permoho- } \\
\text { nan SPPD }\end{array}$ \\
\hline 2 & \begin{tabular}{|l|} 
Menyetujui SPPD dalam rangka \\
Penyusunan Profil Kecamatan
\end{tabular} & & & & SPT, Lembar SPPD & $30 \mathrm{mnt}$. & $\begin{array}{l}\text { Diteruskannya } \\
\text { surat } \\
\text { permohonan }\end{array}$ & \\
\hline 3 & $\begin{array}{l}\text { Menyusun format pendataan } \\
\text { dalam rangka Penyusunan Profil } \\
\text { Kecamatan }\end{array}$ & & & & $\begin{array}{l}\text { Form/Blanko } \\
\text { Pendataan }\end{array}$ & 1 hari. & \begin{tabular}{|l|} 
Disetujuinya \\
surat \\
permohonan \\
data
\end{tabular} & \\
\hline 4 & $\begin{array}{l}\text { Melakukan Pendataan/Meminta } \\
\text { Data melalui Surat }\end{array}$ & & & & $\begin{array}{l}\text { Surat, } \\
\text { Form/Balnko isian } \\
\text { data }\end{array}$ & $\begin{array}{c}3 \text { s.d } 5 \\
\text { hari }\end{array}$ & $\begin{array}{l}\text { Dilakukannya } \\
\text { pendataan }\end{array}$ & $\begin{array}{l}\text { Dapat } \\
\text { dilakukan } \\
\text { dengan } \\
\text { surat }\end{array}$ \\
\hline 5 & Mengolah data yang terkumpul & & & & $\begin{array}{l}\text { Form/Blanko } \\
\text { Pendataan yang } \\
\text { telah terisi }\end{array}$ & 1 hari & \begin{tabular}{|l|} 
Diolahnya \\
data yang \\
terkumpul
\end{tabular} & \\
\hline 6 & $\begin{array}{l}\text { Menyusun laporan hasil } \\
\text { pendataan Profil Kecamatan }\end{array}$ & & & & $\begin{array}{l}\text { Laporan hasil } \\
\text { pendataan }\end{array}$ & 1 hari & $\begin{array}{l}\text { Tersusunnya } \\
\text { laporan }\end{array}$ & \\
\hline 7 & $\begin{array}{l}\text { Menyetujui laporan hasil } \\
\text { pendataan Profil Pendataan }\end{array}$ & & & & $\begin{array}{l}\text { Laporan hasil } \\
\text { pendataan }\end{array}$ & 30 menit & \begin{tabular}{|l|}
$\begin{array}{l}\text { Disetujuinya } \\
\text { laporan hasil } \\
\text { data }\end{array}$ \\
\end{tabular} & \\
\hline 8 & $\begin{array}{l}\text { Memperbanyak hasil } \\
\text { penyusunan profil kecamatan }\end{array}$ & & & & $\begin{array}{l}\text { Data, Papan } \\
\text { Informasi, Spidol }\end{array}$ & $2 \mathrm{Jam}$ & $\begin{array}{l}\text { Tertuangkann } \\
\text { ya data pada } \\
\text { papan }\end{array}$ & \\
\hline 9 & $\begin{array}{l}\text { Mengarsipkan hasil penyusunan } \\
\text { profil kecamatan }\end{array}$ & & & & $\cdot$ & - & 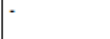 & \\
\hline
\end{tabular}

Gambar 5. Proses bisnis pembuatan profil kecamatan

a. Identifikasi masalah

Identifikasi masalah dilakukan untuk menentukan salah satu masalah dari berbagai masalah apa saja yang terjadi di lokasi penelitian ini, dengan memberikan batasan dari permasalahan yang telah ditentukan.

\section{b. Studi pustaka}

Merupakan suatu cara pencarian data dan mengumpulkan data yang ditujukan pada pencarian data informasi yang terkait dengan penelitian melalui dokumendokumen, baik dokumen tertulis maupun gambar tertulis maupun gambar

\section{c. Pengumpulan data}

Pencarian data dilakukan untuk mencari data-data yang terkait dengan penelitian [19]. Data yang terkait dari penelitian dapat di bagi dua yaitu:

1. Data Utama

Data yang didapatkan langsung dari sumbernya dalam penelitian yang dilakukan.

2. Data Pendukung

Data pendukung merupakan data yang diperoleh atau di dapatkan untuk mendukung data utama yang telah didapat. 


\section{d. Tinjauan kondisi saat ini}

Pada tahap tinjauan kondisi saat ini dapat dilakukan dengan dua tahap yaitu:

1. Proses bisnis

Pada tahap proses bisnis dapat dilakukan identifikasi dan dokumentasi struktur organisasi dan mengartikan fungsi bisnis dengan membuat model proses bisnis awal lalu menggabungkan fungsi-fungsi bisnis tahap awal terhadap unit organisasi agar dapat mengetahui tanggung jawab pada masing-masing unit bagi suatu fungsi bisnis [32].

2. Sistem dan teknologi saat ini

Pada tahap ini dilakukan identifikasi sistem dan teknologi yang digunakan enterprise saat sekarang ini dengan mengumpulkan data penggunaan teknologi informasi.

\section{f. Perancangan arsitektur}

1. Arsitektur data

Pendefinisian entitas data yang digunkan atau diperlukan bagi enterprise.

2. Arsitektur aplikasi

Penetapan dan mengartikan aplikasi-aplikasi yang dibutuhkan dalam pengelolaan data pada enterprise.

3. Arsitektur teknologi

Identifikasi dan pendefinisian teknologi yang dibutuhkan dalam enterprise untuk mengelola data.

\section{Hasil}

a. Identifikasi masalah

Identifikasi masalah yang terjadi di lokasi penelitian mencakup seperti berikut:

1. Penerapan untuk strategi menuju pengembangan e-government belum berjalan dengan baik, sehingga mengakibatkan kepada kualitas pelayanan kepada masyarakat kurang maksimal.

2. Penggunaan sistem informasi saat ini belum bisa dipergunakan secara efektif dikerenakan kurangnya sumber daya manusia untuk membangun sistem tersebut.

3. Pengelolaan data profil kecamatan masih bersifat manual, sehingga memperlambat pengelolaan data dari kecamatan yang ada di Kota Samarinda.

\section{b. Inisialisasi Perencanaan.}

Sebelum pembuatan perencanaan arsitektur enterprise pada kecamatan di Kota Samarinda, perlu dilakukan inisialisasi perencanan untuk mengetahui kondisi awal proses bisnis dan sistem informasi beserta teknologi informasi yang ada pada kecamatan di Kota Samarinda.

Pembuatan EAP difokuskan pada pencarian data yang terkait dengan proses bisnis yang didukung oleh prosedur, alur kerja, deskripsi layanan. Kemudian EAP fokus pada pelayanan dan fasilitas yang diberikan oleh kecamatan saat ini melalui pengembangan e-government dan sistem informasi yang sudah ada dan dimiliki oleh kecamatan pada sistem informasi yang dimiliki oleh kecamatan di Kota Samarinda.

\section{c. Kondisi saat ini}

Pada tahapan ini dilakukan pemetaan terhadap kondisi e-government saat ini di kota Samarinda. Pemetaan dilakukan melalui observasi langsung ke setiap daerah. Dari setiap daerah tersebut, dilihat mengenai pengembangan dan implementasi TIK masing-masing.

Dari hasil obserbasi langsung ke lokasi penelitan yaitu kecamatan yang ada di Kota Samarinda, masih banyaknya kecamatan-kecamatan yang masih belum memanfaatkan sistem informasi dan teknologi informasi, sedangkan dari [3] meminta semua instansi pemerintahan menggunakan sistem informasi dan teknologi informasi untuk meningkatkan pelayanan kepada masyarakat. Hal ini menimbulkan gap (jarak) yang harus diselesaikan. Melihat dari hasil observasi tersebut, perancangan e-government secara menyeluruh memang harus dilakukan agar pengembangan sistem informasi dan TIK dapat terpantau secara terpusat dan dapat dikoordinasikan dengan baik.

\section{d. Proses bisnis yang berjalan di kecamatan}

Proses bisnis diidentifikasi tanpa memperhatikan tanggung jawab organisasi terhadapnya, tetapi berdasarkan bisnis yang ada pada kecamatan. Berikut ini merupakan proses bisnis pelayanan publik pada kecamatan di Kota Samarinda

1. Proses bisnis surat masuk

Dari gambar 4 dapat dijelaskan proses bisnis yang terjadi di kecamatan yang ada di Kota Samarinda pada proses bisnis surat masuk, dari gambar 4 dapat diartikan bahwa proses surat masuk dilakukan oleh bagian administrasi umum, subbag umum, dan sekcam, setelah melewati bagian diatas lalu surat masuk akan diterima pada unit/seksi yang surat tuju.

2. Proses bisnis pembuatan profil kecamatan

Dari gambar 5 dapat dijelaskan proses pembuatan profil kecamatan yang ada di Kota Samarinda, dari awal penyusunan profil kecamatan sampai mengarsipkan hasil penyusunan profil kecamatan. Bagian-bagian yang terlibat langsung pada pembuatan profil kecamatan yaitu, camat, kasi perintahan, dan staf untuk memperbanyak hasil dari laporan pengumpulan data untuk profil kecamatan yang ada di Kota Samarinda.

\section{e. Sistem dan teknologi Saat ini}

Dari analisis yang telah dilakukan pada kecamatan yang ada di Kota Samarinda, system, dan teknologi yang ada sekarang pada kecamatan yang ada di Kota Samarinda yaitu:

1. Aplikasi kepegawaian

Aplikasi kepegawaian berguna untuk mengetahui informasi seluruh pegawai yang ada di kecamatan yang ada di Kota Samarinda.

2. Aplikasi SIM presensi sidik jari

Aplikasi ini digunakan untuk presensi pegawai pada saat datang dan pegawai pulang pada kecamatan yang ada di Kota Samarinda, aplikasi ini digunakan untuk mengetahui kinerja pegawai dalam hal kehadiran.

3. Infrastruktur teknologi

Infrastruktur teknologi yang dimiliki oleh kecamatan yang ada di Kota Samarinda saat ini yaitu, 
Tabel 1. Infrastruktur Teknologi

\begin{tabular}{|c|c|c|c|c|}
\hline No. & \multicolumn{2}{|c|}{ Kelompok Teknologi } & \multicolumn{2}{|r|}{ Rincian } \\
\hline 1 & \multicolumn{2}{|c|}{ Perangkat Keras } & \multicolumn{2}{|c|}{$\begin{array}{l}100 \text { buah PC } \\
200 \text { Buah Laptop }\end{array}$} \\
\hline 2 & \multicolumn{2}{|c|}{ Perangkat Lunak } & \multicolumn{2}{|l|}{$\begin{array}{l}\text { Windon } \\
\text { Mysql } \\
\text { PHP }\end{array}$} \\
\hline 3 & \multicolumn{2}{|c|}{ Komunikasi } & \multicolumn{2}{|c|}{$\begin{array}{l}\text { LAN } \\
\text { WiFi } \\
\text { Internet }\end{array}$} \\
\hline \multicolumn{5}{|c|}{ Tabel 2. Analisis rantai pada kecamatan } \\
\hline \multicolumn{2}{|c|}{$\begin{array}{l}\text { Logistik } \\
\text { masukan }\end{array}$} & \multicolumn{2}{|l|}{ Proses } & $\begin{array}{r}\text { Logistik } \\
\text { keluaran } \\
\end{array}$ \\
\hline \multicolumn{2}{|c|}{$\begin{array}{l}\text { Pengelolaan surat } \\
\text { masuk }\end{array}$} & \multicolumn{2}{|c|}{$\begin{array}{ll} & \text { Rekap data surat masuk } \\
\text { Pengelolaan surat masuk } \\
\text { Pelayanan surat masuk } \\
\text { Laporan surat masuk }\end{array}$} & 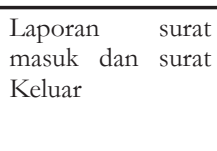 \\
\hline \multicolumn{2}{|c|}{$\begin{array}{l}\text { Pengelolaan surat } \\
\text { keluar }\end{array}$} & \multicolumn{3}{|c|}{$\begin{array}{l}\text { Rekap data surat keluar } \\
\text { Pengelolaan surat keluar } \\
\text { Pelayanan surat keluar } \\
\text { Laporan surat keluar }\end{array}$} \\
\hline \multicolumn{2}{|c|}{$\begin{array}{l}\text { Pembuatan profil } \\
\text { kecamatan }\end{array}$} & \multicolumn{2}{|c|}{$\begin{array}{l}\text { Rekap data profil } \\
\text { Pengelolaan data profil }\end{array}$} & $\begin{array}{l}\text { Laporan } \\
\text { kecamatan }\end{array}$ \\
\hline \multicolumn{2}{|c|}{$\begin{array}{l}\text { P e m b u a t a n } \\
\text { mo nog raf i } \\
\text { kecamatan }\end{array}$} & $\begin{array}{l}\text { 1. Rekap data pe } \\
\text { 2. Pengelolaan } \mathrm{d} \\
\text { penduduk } \\
\text { 3. Laporan }\end{array}$ & luduk & $\begin{array}{l}\mathrm{L} \text { a } \mathrm{p} \text { o } \mathrm{r} \text { a } \mathrm{n} \\
\mathrm{m} \text { o } \mathrm{n} \text { o g r a f i } \\
\text { kependudukan }\end{array}$ \\
\hline
\end{tabular}

Tabel 3. Four Stage Life Cycle berdasarkan proses bisnis kecamtan di kota Samarinda

\begin{tabular}{|c|c|c|c|c|}
\hline \multirow{2}{*}{ Model Bisnis } & \multicolumn{4}{|c|}{ Tahapan-Tahapan Siklus Hidup } \\
\hline & Kebutuhan & Pencapaian & Pemeliharaan & Pengehentian \\
\hline $\begin{array}{l}\text { Pengelolaan surat } \\
\text { masuk }\end{array}$ & $\begin{array}{l}\text { Perencanaan } \\
\text { pengelolaan surat } \\
\text { masuk }\end{array}$ & Pengelolaan surat masuk & $\begin{array}{l}\text { Pemeliharaan surat } \\
\text { masuk }\end{array}$ & Laporan surat masuk \\
\hline $\begin{array}{l}\text { Pengelolaan surat } \\
\text { keluar }\end{array}$ & $\begin{array}{l}\text { Perencanaan } \\
\text { pengelolaan surat } \\
\text { masuk }\end{array}$ & Pengelolaan surat masuk & $\begin{array}{l}\text { Pemeliharaan surat } \\
\text { masuk }\end{array}$ & Laporan surat masuk \\
\hline $\begin{array}{l}\text { Pembuatan } \\
\text { laporan tahunan }\end{array}$ & $\begin{array}{l}\text { Perencanaan } \\
\text { pembuatan laporan } \\
\text { tahunan }\end{array}$ & $\begin{array}{l}\text { Laporan kegiatan } \\
\text { pertahun }\end{array}$ & $\begin{array}{l}\text { Pemeliharaan laporan } \\
\text { tahunan }\end{array}$ & $\begin{array}{l}\text { Cetak buku laporan } \\
\text { tahunan }\end{array}$ \\
\hline $\begin{array}{l}\text { Pembuatan profil } \\
\text { kecamatan }\end{array}$ & $\begin{array}{l}\text { Perencanaan } \\
\text { penyelenggara pebuatan } \\
\text { profil kecamatan }\end{array}$ & $\begin{array}{l}\text { Pengelolaan data profil } \\
\text { kecamatan } \\
\text { Pelayanan profil } \\
\text { kecamatan }\end{array}$ & $\begin{array}{l}\text { Pemeliharaan data } \\
\text { profil kecamatan }\end{array}$ & $\begin{array}{l}\text { Laporan profil } \\
\text { kecamatan }\end{array}$ \\
\hline $\begin{array}{l}\text { Pembuatan } \\
\text { monografi } \\
\text { penduduk }\end{array}$ & $\begin{array}{l}\text { Perencanaan } \\
\text { penyelenggara pebuatan } \\
\text { profil kecamatan }\end{array}$ & $\begin{array}{l}\text { Pengadaan } \\
\text { datamonografi } \\
\text { kependudukan } \\
\text { Pengelolaan } \\
\text { data monografi } \\
\text { kependudukan }\end{array}$ & $\begin{array}{l}\text { Pemeliharaan } \\
\text { data monografi } \\
\text { kependudukan }\end{array}$ & $\begin{array}{l}\text { Laporan monografi } \\
\text { kependudukan }\end{array}$ \\
\hline
\end{tabular}

\section{f. Analisis rantai}

Analisis rantai pada kecamatan yang ada di Kota Samarinda terdiri dari aktivitas utama dan aktivitas pendukung. Di mana aktivitas utama adalah proses bisnis yang ada pada kecamatan di Kota Samarinda dan aktivitas pendukung adalah objek-objek yang mendukung aktivitas utama guna mendukung tercapainya target yang diinginkan dan analisis rantai dapat dijelaskan pada tabel 2 di bawah ini.
Fungsi-fungsi utama pada kecamatan di Kota Samarinda yang diperoleh sebagai hasil analisis nilai rantai Porter kemudian diturunkan atau didekomposisi sehingga mendapatkan fungsi-fungsi turunan menggunakan tool Four Stage Life Cycle Business System Planning. Dengan menggunakan Four Stage Life Cycle, yang ditunjukkan pada tabel 3 di bawah ini. 
Tabel 4 Kandidat entitas data

\begin{tabular}{ll}
\hline Entitas Bisnis & Entitas Data \\
\hline Pengelolaan surat masuk & Surat_masuk \\
& Staf \\
& Instansi \\
& laporan \\
Pengelolaan surat keluar & Surat_keluar \\
& Staf \\
& Instansi \\
& laporan \\
Pembuatan laporan & Subbagian \\
tahunan & Anggaran \\
& Kegiatan \\
& Kepegawaian \\
& Pengeluaran \\
Pembuatan profil & Pemasukan \\
kecamatan & Instansi \\
Monografi penduduk & Profil kecamatan \\
& Data_penduduk \\
\hline
\end{tabular}

Tabel 5. Komunitas Aplikasi

\begin{tabular}{|c|c|c|}
\hline No & Komunitas Aplikasi & Jenis Aplikasi \\
\hline 1 & $\begin{array}{l}\text { Pengelolaan surat } \\
\text { masuk }\end{array}$ & $\begin{array}{l}\text { 1. Aplikasi surat masuk } \\
\text { 2. Aplikasi kearsipan surat masuk }\end{array}$ \\
\hline 2 & $\begin{array}{l}\text { Pengelolaan surat } \\
\text { keluar }\end{array}$ & $\begin{array}{l}\text { a. Aplikasi surat keluar } \\
\text { b. Aplikasi kearsipan surat masuk }\end{array}$ \\
\hline 3 & $\begin{array}{l}\text { Pembuatan laporan } \\
\text { tahunan kecamatan }\end{array}$ & 1. Aplikasi laporan kecamatan \\
\hline 4 & $\begin{array}{l}\text { Pembuatan profil } \\
\text { kecamatan }\end{array}$ & $\begin{array}{l}\text { a. Sistem informasi kecamatan } \\
\text { b. Sistem informasi kelurahan }\end{array}$ \\
\hline 5 & $\begin{array}{l}\text { monografi Pembuatan } \\
\text { kepandudukan }\end{array}$ & $\begin{array}{l}\text { 1. Aplikasi monografi kependudukan } \\
\text { kecamatan }\end{array}$ \\
\hline
\end{tabular}

Tabel 6. Analisis Dampak

\begin{tabular}{|c|c|c|c|c|c|c|}
\hline $\begin{array}{l}\text { Subyek Basis } \\
\text { Data }\end{array}$ & $\begin{array}{l}\text { Kandidat } \\
\text { Aplikasi }\end{array}$ & $\begin{array}{c}\text { Sistem Legacy } \\
\text { Terkait }\end{array}$ & & & & Analisis Dampak \\
\hline & & & 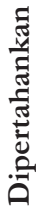 & 苟 & $\stackrel{\pi}{\pi}^{\frac{\pi}{2}}$ & Keterangan \\
\hline $\begin{array}{l}\text { Pengelolaan profil } \\
\text { kecamatan }\end{array}$ & $\begin{array}{l}\text { Sistem } \\
\text { informasi } \\
\text { profil } \\
\text { kecamatan }\end{array}$ & $\begin{array}{l}\text { Aplikasi profil } \\
\text { kecamatan }\end{array}$ & & & $\sqrt{ }$ & $\begin{array}{l}\text { Sistem yang dibuat untuk memberikan informasi- } \\
\text { informasi yang terkait dengan kecamatan }\end{array}$ \\
\hline $\begin{array}{l}\text { Pengelolaan surat } \\
\text { masuk }\end{array}$ & $\begin{array}{l}\text { Sistem } \\
\text { pengelolaan } \\
\text { surat masuk }\end{array}$ & $\begin{array}{l}\text { Aplikasi } \\
\text { pengelolaan } \\
\text { surat masuk }\end{array}$ & & & $\sqrt{ }$ & $\begin{array}{l}\text { Sistem Informasi yang digunakan untuk mengolah } \\
\text { surat masuk }\end{array}$ \\
\hline $\begin{array}{l}\text { Sistem } \\
\text { pengelolaan surat } \\
\text { keluar }\end{array}$ & $\begin{array}{l}\text { Sistem } \\
\text { pengelolaan } \\
\text { surat keluar }\end{array}$ & $\begin{array}{l}\text { Aplikasi } \\
\text { Pengelolaan } \\
\text { surat keluar }\end{array}$ & $\sqrt{ }$ & & & $\begin{array}{l}\text { Sistem Informasi yang digunakan untuk mengolah } \\
\text { surat keluar }\end{array}$ \\
\hline $\begin{array}{l}\text { Pengelolaan } \\
\text { data monografi } \\
\text { pendududuk }\end{array}$ & $\begin{array}{l}\text { Sistem } \\
\text { informasi data } \\
\text { monografi } \\
\text { penduduk }\end{array}$ & $\begin{array}{l}\text { Aplikasi } \\
\text { pengelolaan } \\
\text { data monografi } \\
\text { pendududuk }\end{array}$ & & & $\sqrt{ }$ & $\begin{array}{l}\text { Sistem informasi yang digunakan untuk mengelola data } \\
\text { monografi kependudukan }\end{array}$ \\
\hline $\begin{array}{l}\text { Pengelolaan } \\
\text { laporan tahunan }\end{array}$ & $\begin{array}{l}\text { Sistem } \\
\text { informasi } \\
\text { laporan } \\
\text { tahunan }\end{array}$ & $\begin{array}{l}\text { Aplikasi laporan } \\
\text { kegiatan }\end{array}$ & & $\sqrt{ }$ & & $\begin{array}{l}\text { Sistem informasi yang digunakan untuk pengelolaan } \\
\text { pebuatan laporan kegiatan tahunan }\end{array}$ \\
\hline
\end{tabular}


Tabel 7. Matriks Unit Organisasi dan Aplikasi

\begin{tabular}{|c|c|c|c|c|c|c|c|c|}
\hline Unit Organisasi & 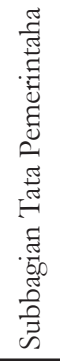 & 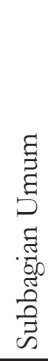 & 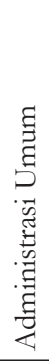 & 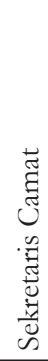 & 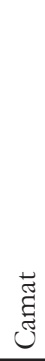 & 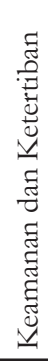 & 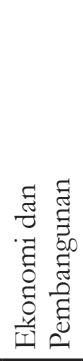 & 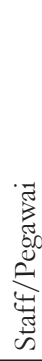 \\
\hline Sistem informasi laporan tahunan & & $\sqrt{ }$ & $\sqrt{ }$ & $\sqrt{ }$ & $\sqrt{ }$ & & & $\sqrt{ }$ \\
\hline $\begin{array}{l}\text { Sistem pengelolaan data monografi } \\
\text { kependudukan }\end{array}$ & $\sqrt{ }$ & & $\sqrt{ }$ & $\sqrt{ }$ & & & & $\sqrt{ }$ \\
\hline Sistem profil kecamatan dan kelurahan & & & $\sqrt{ }$ & & & $\sqrt{ }$ & & $\sqrt{ }$ \\
\hline Sistem surat masuk & & $\sqrt{ }$ & $\sqrt{ }$ & & & & & $\sqrt{ }$ \\
\hline Sistem surat keluar & & $\sqrt{ }$ & & & $\sqrt{ }$ & & & \\
\hline
\end{tabular}

Tabel 9. Daftar platform teknologi

\begin{tabular}{|c|c|c|c|c|c|}
\hline No & Kelompok Aplikasi & $\begin{array}{l}\text { Kelompok } \\
\text { Teknologi }\end{array}$ & & Jenis Teknologi & Rincian \\
\hline \multirow[t]{9}{*}{1} & $\begin{array}{l}\text { Sistem pengelolaan } \\
\text { surat masuk, sistem } \\
\text { pengelolaan surat keluar, } \\
\text { sistem pengelolaan surat } \\
\text { keluar, sistem informasi } \\
\text { profil kecamatan, } \\
\text { sistem informasi } \\
\text { pengelolaan monografi } \\
\text { kependudukan }\end{array}$ & Perangkat keras & 1.1 & Komputer & $\begin{array}{l}\text { 1.1.1 PC Intel/Sejenis } \\
\text { a. HDD } 500 \mathrm{~Gb} \\
\text { b. RAM } 2 \mathrm{~Gb} \\
\text { c. Core } 2 \text { Duo } \\
\text { 1.1.2 Laptop } \\
\text { a. HDD } 500 \mathrm{~Gb} \\
\text { b. RAM } 2 \mathrm{~Gb} \\
\text { c. Intel Core I } 3 \\
\text { 1.1.2 Monitor } \\
\text { 1.1.3 Keyboard } \\
\text { 1.1.4 Mouse }\end{array}$ \\
\hline & & & 1.2 & Perangkat I/O & $\begin{array}{l}\text { 1.2.1 Printer } \\
\text { 1.2.2 Scanner }\end{array}$ \\
\hline & & & 1.3 & Media Penyimpanan & $\begin{array}{l}\text { 1.3.1 Magnetik CD } \\
\text { 1.3.2 Flasdisk } \\
\text { 1.3.3 Hardisk eksternal }\end{array}$ \\
\hline & & Perangkat Lunak & 2.1 & Sistem operasi & $\begin{array}{l}\text { 2.1.1 Windows } 10 \\
\text { 2.1.2 Linux }\end{array}$ \\
\hline & & & 2.2 & Basis Data & $\begin{array}{l}\text { 2.2.1 MySQL } \\
\text { 2.2.2 XAMPP }\end{array}$ \\
\hline & & & 2.3 & Bahasa Pemrograman & 2.3.1 PHP \\
\hline & & & 2.4 & Lain-lain & $\begin{array}{l}\text { 2.4.1 Ms. Office } \\
\text { 2.4.2 Adobe reader } \\
\text { 2.4.3 Adobe Photosop } \\
\text { 2.4.4 Mozilla Firefo }\end{array}$ \\
\hline & & Komunikasi & $3.1 \mathrm{Ja}$ & ringan & $\begin{array}{l}\text { 1.3.1 Wifi } \\
\text { 1.3.2 Jaringan LAN }\end{array}$ \\
\hline & & & $3.2 \mathrm{P}$ & erangkat Jaringan & $\begin{array}{l}\text { 3.2.1 Router } \\
\text { 3.2.2 Swicht }\end{array}$ \\
\hline
\end{tabular}

Dari tabel 3 dijelaskan bahwa model bisnis pengelolaan surat masuk dan surat keluar mempunyai pembuatan profil kecamatan dan memiliki pencapaian pengelolaan dan pelayanan data profil kecamatan dan akhir dari semua proses tersebut adalah laporan buku surat keluar pada akhirnya akan membuat buku laporan surat masuk, model bisnis pembuatan profil kecamatan mempunyai kebutuhan untuk perencanaan akhir dari semua proses tersebut adalah laporan buku profil kecamatan 
Tabel 10. Portofolio Aplikasi

\begin{tabular}{ll}
\hline \multicolumn{1}{c}{ Strategis } & Potensial Tinggi \\
\hline Sistem informasi kecamatan & $\begin{array}{l}\text { Aplikasi pengelolaan } \\
\text { data monografi } \\
\text { kependudukan }\end{array}$ \\
\hline \multicolumn{1}{c}{ Operasional Kunci } & Pendukung \\
\hline $\begin{array}{l}\text { Aplikasi pengelolaan surat } \\
\text { masuk }\end{array}$ & $\begin{array}{l}\text { Aplikasi laporan } \\
\text { tahunan kegiatan } \\
\text { kecamatan }\end{array}$ \\
$\begin{array}{l}\text { Aplikasi pengelolaan surat } \\
\text { keluar }\end{array}$ & \\
\hline
\end{tabular}

Tabel 11. Rencana Implementasi

\begin{tabular}{cll}
\hline No. & \multicolumn{1}{c}{ Daftar Aplikasi } & \multicolumn{1}{c}{ Kategori Portofolio Aplikasi } \\
\hline 1 & Sistem informasi kecamatan & Strategis \\
2 & Sistem informasi kelurahan & Strategis \\
3 & Aplikasi pengeloaan data monografi kependudukan & Potensial tinggi \\
4 & Aplikasi pengelolaan surat masuk & Operasional kunci \\
5 & Aplikasi pengelolaan surat keluar & Operasional kunci \\
6 & Aplikasi laporan tahunan kegiatan kecamatan & Pendukung \\
\hline
\end{tabular}

\section{g. Arsitektur data}

Dalam pembuatan arsitektur data, jenis data utama yang mendukung fungsi dari proses bisnis yang telah diartikan harus tetapkan dan diartikan. Berikut ini merupakan daftar entitas data yang dipakai oleh kecamatan yang ada di Kota Samarinda dapat dilihat pada tabel 4 dibawah ini.

\section{h. Arsitektur aplikasi}

Maksud dari arsitektur aplikasi untuk mengartikan aplikasi-aplikasi yang akan dipergunakan untuk mengelola data dan mendukung fungsi bisnis yang ada pada kecamatan. Melihat dari kerangka kerja zachman framework di mana arsitektur aplikasi berada pada kolom fungsi perspektif arsitek, yang mana arsitektur aplikasi merupakan sebuah model yang mendefinisikan kondisi awal aplikasi yang ada pada Kecamatan di Kota Samarinda, yang nantinya dapat dijadikan sebagai dasar dalam memilih penerapan aplikasi yang akan dikembangkan. Model arsitektur aplikasi yang terdapat pada kecamatan di Kota Samarinda dapat didefinisikan dengan beberapa model sebagai berikut:

1. Daftar kandidat aplikasi

Tahap awal dari pembuatan arsitektur aplikasi adalah membuat daftar target kandidat aplikasi, dapat dilihat pada tabel 5.

Pada tabel 5 di atas dijabarkan daftar kandidat aplikasi yang terbagi menjadi 5 sistem informasi dan 8 aplikasi. Di mana daftar kandidat aplikasi di atas dibagi menjadi 2 bagian yaitu kelompok aplikasi merupakan sistem informasi utama dari aplikasi-aplikasi yang dibangun untuk digunakan sesuai dengan bidangnya. Kemudian kandidat aplikasi merupakan aplikasiaplikasi yang terdapat dalam kelompok aplikasi atau sistem informasi utama.

2. Analisis dampak

Analisis dampak merupakan penunjukan aplikasi terhadap sistem yang ada sekarang ini [33]. Kandidat aplikasi yang baru tentu memiliki dampak terhadap aplikasi yang telah ada sebelumnya (system legacy). Untuk itu maka perlu adanya analisis dampak dari penunjukan aplikasi baru terhadap sistem legacy. Hasil analisis adalah penunjukan atas pilihan apakah tetap dipergunakan, diubah atau bahkan dibuat dengan pengembangan baru, dapat dilihat pada tabel 6 di bawah ini.

Tahapan selanjutnya untuk pembangunan arsitektur aplikasi adalah melakukan distribusi arsitektur organisasi. Tahapan ini dilakukan dengan membuat matriks aplikasi vs organisasi. Tujuan dari tahapan ini adalah untuk mengidentifikasi aplikasi secara langsung didukung atau dilakukan oleh organisasi. Hubungan aplikasi dan organisasi dapat disajikan dalam tabel 7 .

\section{i. Arsitektur teknologi}

Pembuatan arsitektur teknologi yaitu dengan mengartikan prinsip dan dasar teknologi utama yang diperlukan untuk menyediakan lingkungan yang membantu aplikasi. Pada tabel di bawah ini menjelaskan prinsip dan landasan teknologi yang ada di kecamatan dan kelurahan Kota Samarinda, dapat dilihat pada tabel 9 di bawah ini.

\section{j. Portofolio aplikasi}

Berdasarkan alur pembangunan portofolio yang telah dikemukakan oleh ward adalah pembangunan portofolio terbagi menjadi 4 aspek yaitu:

1. Aplikasi strategis: aplikasi bersifat penting untuk berkelanjutan strategi bisnis di masa yang akan datang.

2. Aplikasi operasional kunci: aplikasi yang dapan menjadi jaminan oleh enterprise untuk mencapai target yang sesuai diinginkan enterprise.

3. Aplikasi berpotensial tinggi: kesuksesan di masa yang akan datang.

4. Aplikasi pendukung: aplikasi yang dinilai penting namun tidak bersifat kritikal untuk kesuksesan enterprise.

Maka berikut ini adalah pengelompokkan arsitektur aplikasi untuk yang dikelompokkan oleh 4 aspek: 


\section{k. Urutan implementasi}

Berdasarkan alur yang telah dilakukan, maka dapat dilakukan urutan penerapan aplikasi yang dibangun atau di kembangkan pada kecamatan di Kota Samarinda, dapat dilihat pada tabel 11 .

\section{Kesimpulan}

Dari hasil penelitian ini adalah sebuah permodelan arsitektur enterprise dan berbentuk rencana implementasi pada pelayanan masyakarat dalam penggunaan teknologi informasi dan sistem informasi pada kecamatan yang ada di Kota Samarinda yang dapat digunakan untuk mendukung pelayanan publik pada kecamatan yang ada di Kota Samarinda sehingga terwujudnya keselarasan antara sistem informasi dan teknologi informasi dan pelayanan publik pada kecamatan di Kota Samarinda.

\section{Daftar Pustaka}

[1] A. Subhan, Pelaksanaan Transparansi Pemerintahan Daerah dalam Perspektif Jaringan (Studi tentang Jaringan Antar Organisasi dalam Penyediaan Informasi Anggaran melalui Website Pemerintah Provinsi), no. August 2017. 2018.

[2] Y. Utami, A. Nugroho, and A. F. Wijaya, "Perencanaan Strategis Sistem Informasi dan Teknologi Informasi pada Dinas Perindustrian dan Tenaga Kerja Kota Salatiga," J. Teknol. Inf. dan Ilmu Komput., vol. 5, no. 3, p. 253, 2018.

[3] Presiden Republik Indonesia, "Instruksi Presiden Republik Indonesia Nomor 3 tahun 2003," Instr. Pres., no. Undang-Undang Informasi dan Transaksi Elektronik, pp. 1-25, 2003.

[4] T. F. Gafar, "Pemanfaatan Teknologi Informasi dan Komunikasi (E-Government) dalam Pelayanan Kependudukan," J. ALBOACEN, vol. Volume 1, no. February 2018, pp. 0-27, 2013.

[5] A. Cahyadi, "Konsep dan Permasalahan Latar Belakang dan Konsep," J. WINNERS, pp. 1-12, 2003.

[6] Al-Hashmi and A. Darem, "Understanding Phases of E-government Project," Emerg. Technol. E-Government, pp. 152-157, 2008.

[7] E. A. Sosiawan, "Tantangan dan Hambatan dalam Implementasi E-Government di Indonesia," Semin. Nas. Inform., vol. 2008, no. semnasIF, pp. 99-108, 2008.

[8] P. Daerah, "Peraturan Daerah Kota Samarinda Nomor 2 Tahun 2014 Tentang Rencana Tata Ruang Wilayah Kota Samarinda Tahun 20142034," no. 6, pp. 1-78, 2014.

[9] Y. Miftahuddin, M. Ichwan, and M. Musrini, "Penerapan Metode EAP (Enterprise Architecture Planning)," J. Inform., vol. 4, no. 1, 2013.

[10] S. . Spewak, S. H., Hill, "Enterprise Architecture Planning," John Wiley Sons, Inc., 1992.

[11] K. Surendro, "Pemanfaatan Enterprise Architecture Planning untuk Perencanaan Strategis Sistem Informasi," J. Inform., vol. 8, no. 1, pp. 1-9, 2007.
[12] T. Kristanto, "Enterprise Architecture Planning untuk Proses Pengelolaan Manajemen Aset dengan Zachman Framework," Regist. J. Ilm. Teknol. Sist. Inf., vol. 2, no. 2, p. 98, 2016.

[13] S. Bambang Widodo, "Pengembangan Blueprint It dengan Zachman Framework di STP Trisakti," J. Sist. Inf. (Journal Inf. Syst. 1/13 (2017), 49-66 DOI http//dx.doi.org/10.21609/jsi.v13i1.528, vol. 12, pp. 82-89, 2016.

[14] A. B. Hikmah, "Mendefinisikan Enterprise Architecture Planning dalam Perencanaan Integrasi Sistem Informasi Perpustakan Sekolah,” J. Inform., vol. I, no. 2, pp. 130-135, 2014.

[15] A. L. Tungadi and S. Suharjito, "Developing IT Strategic Planning Using Mobile Enterprise Architecture in the Academic Process of Atma Jaya Makassar University," ComTech Comput. Math. Eng. Appl., vol. 8, no. 1, p. 29, 2017.

[16] S. Bambang Widodo, "Pengembangan Blueprint It dengan Zachman Framework di STP Trisakti," J. Sist. Inf., vol. 13, no. 1, pp. 49-59, 2017.

[17] J. Bastari, "Pemanfaatan Enterprise Architecture Planning pada Akper Harum Jakarta," Pilar Nusa Mandiri, vol. IX, no. 2, pp. 153-164, 2013.

[18] A. Khumaidi, A. Suryana, and E. Ridhawati, "Pada STMIK Pringsewu dengan Menggunakan Metodologi Enterprise Architecture Planning (Eap)," Semin. Nas. Teknol. Inf. dan multi media, vol. 3, pp. 6-7, 2016.

[19] B. H. Purnomo, "Metode dan Teknik Pengumulan Data dalam Penelitian Tindakan Kelas (Classroom Action Research)," vol. 8, p. 6, 2011.

[20] M. B. W. Indra Permana Solihin, "Perencanaan Strategik Sistem Informasi dan Teknologi Informasi (Si/Ti) dengan Framework Zachman di Universitas," Pros. SINTAK 2017, ISBN 978 602-8557-20-7, pp. 259-269, 2017.

[21] R. Herdiansyah, "Enterprise Architecture Planning Sistem Informasi Usaha Kepariwisataan Berbasis Web," vol. 2, no. 2, pp. 65-76, 2017.

[22] A. T. Astri Veviyana, "Pembuatan Enterprise Architecture Planning dengan Menggunakan Kerangka Kerja Zachman di Majelis Pustaka dan Informasi PP Muhammadiyah Yogyakarta," Astri Veviyana, Ali Tarmuji, 2010.

[23] B. F. Florensia et al., "Enterprise Architecture di Televisi Republik Indonesia (TVRI) Jawa Timur.”

[24] D. Saputra, "Perancangan Enterprise Architecture Zachman Framework untuk Jasa Layanan Pasang Baru dan Tambah Daya Listrik pada Perusahaan Jasa Listrik Swasta," J. Khatulistiwa Inform., vol. 3, no. 1, 2015.

[25] A. P. Sahida and H. C. Rustamaji, "Sistem Informasi Pemerintahan Desa Menggunakan Framework Zachman Studi Kasus Desa Triwidadi, Pajangan, Bantul," Telematika, vol. 14, no. 02, pp. 89-99, 2017.

[26] R. Yunis and Theodora, "Penerapan Enterprise Architecture Framework untuk Pemodelan," JSM STMIK Mikroskil, vol. 13, no. 2, pp. 159-168, 
2012.

[27] Taryana Suryana, "Perancangan Arsitektur Teknologi Informasi dengan Pendekatan Enterprise Architecture Planning," J. Ilm. Unikom, vol. 10, no. 2, pp. 223-236, 2012.

[28] K. Surendro, "Pemanfaatan Enterprise Architecture Planning untuk Perencanaan Strategis Sistem Informasi," J. Inform., vol. 8, no. 1, pp. 1-9, 2007.

[29] S. Buckl, A. M. Ernst, F. Matthes, R. Ramacher, and C. M. Schweda, "Using Enterprise Architecture Management Patterns to Complement TOGAF," Proc.-13th IEEE Int. Enterp. Distrib. Object Comput. Conf. EDOC 2009, no. May, pp. 34 41, 2009.

[30] I. K. W. Adnyana, Y. H. Putra, and D. Rosiyadi, "Pengembangan Layanan Sistem Informasi dengan Enterprise Architecture Planning (Studi
Kasus: Rumah Sakit Umum Daerah Kota Bandung)," J. INKOM, vol. 9, no. 2, p. 73, 2016.

[31] I. L. Sardi and K. Surendro, "Rekomendasi Perancangan Arsitektur Enterprise Pascamerger (Studi kasus : Universitas Telkom)," Ind. J. Comput., vol. 1, no. February, pp. 61-76, 2016.

[32] S. K. Sari and A. Asniar, "Analisis dan Pemodelan Proses Bisnis Prosedur Pelaksanaan Proyek Akhir Sebagai Alat Bantu Identifikasi Kebutuhan Sistem," J. Inform. dan Elektron., vol. 7, no. 2, pp. 143-152, 2015.

[33] Ramadiani, D. M. Khairina, and A. K. Aziz, "Perancangan E-Government Kelurahan Sempaja Timur Menggunakan Enterprise Architecture Planning," Pros. Semin. Ilmu Komput. dan Teknol. Inf., vol. 2, no. 1, pp. 1-8, 2017. 